\title{
Systemic Expression of Vascular Endothelial Growth Factor in Patients with Cerebral Cavernous Malformation Treated by Stereotactic Radiosurgery
}

\author{
Sang-Jin Park, M.D., Seong-Hyun Park, M.D., Ph.D. \\ Department of Neurosurgery, Kyungpook National University Hospital, Daegu, Korea
}

\begin{abstract}
Objective : Increased expression of angiogenic factors, such as vascular endothelial growth factor (VEGF), is associated with the pathogenesis of cerebral cavernous malformations (CCMs). The purpose of this study was to investigate plasma levels of VEGF in normal subjects and in patients with CCM and to evaluate change in these levels following stereotactic radiosurgery (SRS).

Methods : Peripheral venous blood was collected from 6 patients with CCM before SRS using Gamma Knife and at the 1 week, 1 month, 3month, and 6 month follow-up visits. Plasma VEGF levels were measured using commercially available enzyme-linked immunosorbent assay kits. Peripheral blood samples were obtained from 10 healthy volunteers as controls.

Results : Mean plasma VEGF level of $41.9 \mathrm{pg} / \mathrm{mL}$ (range, $11.7-114.9 \mathrm{pg} / \mathrm{mL}$ ) in patients with CCM at baseline was higher than that of the healthy controls (29.3 pg/mL, range, 9.2-64.3 pg/mL), without significant differences between CCM patients and controls ( $p=0.828)$. Plasma VEGF level following SRS dropped to $24.6 \mathrm{pg} / \mathrm{mL}$ after 1 week, and decreased to $18.5 \mathrm{pg} / \mathrm{mL}$ after 1 month, then increased to $24.3 \mathrm{pg} / \mathrm{mL}$ after 3 months, and $32.6 \mathrm{pg} / \mathrm{mL}$ after 6 months. Two patients suffering from rebleeding after SRS showed a higher level of VEGF at 6 months after SRS than their pretreatment level.

Conclusion : Plasma VEGF levels in patients with CCM were elevated over controls at baseline, and decreased from baseline to 1 month after SRS and increased further for up to 6 months. Theses results indicated that anti-angiogenic effect of SRS might play a role in the treatment of CCMs.
\end{abstract}

Key Words : Cavernous malformation · Gamma Knife $\cdot$ Stereotactic radiosurgery · Vascular endothelial growth factor.

\section{INTRODUCTION}

The multifunctional cytokine vascular endothelial growth factor (VEGF) acts as a vascular endothelial cell-specific mitogen and is a major regulator of angiogenesis ${ }^{2,8,21,34)}$. VEGF is expressed and secreted by numerous tumor and normal tissue cell lines of animal and human origin ${ }^{36)}$. The tyrosine-kinase receptors encoded by the Flt and KDR/Flk-1 genes were found to function as the VEGF receptors. Both receptors have been reported as exclusively expressed on the cell surface of vascular endothelium ${ }^{11)}$. The fact that VEGF has not been localized in endothelial cells indicates a central paracrine mechanism of action. VEGF is secreted by non endothelial cells under the influence of other cytokines such as platelet-derived growth factor. Thus VEGF appears to be a major regulator for inducing angiogenesis and is a molecule of potential therapeutic value ${ }^{3,21,29)}$.
VEGF is expressed abundantly during embryonic development but is absent in most normal adult vascular beds, including the cerebral vasculature ${ }^{1,32)}$. A variety of cells can synthesize and secrete VEGF under pathological conditions, including fibrocytes, myocytes, and astrocyte ${ }^{7}$. VEGF is expressed during the early phases of atherogenesis and in a wide variety of pathological processes, including inflammation and tumor growth ${ }^{1,6,32)}$. Hypoxia is thought to be a powerful trigger for the up-regulation of VEGF expression and might represent an initiating signal in the cascade of angiogenesis ${ }^{30)}$.

Several workers have hypothesized a role for VEGF in the pathophysiology of cerebral cavernous malformations (CCMs ${ }^{4,35)}$. Endothelial proliferation induced by VEGF is an important element in the underlying developmental and pathogenetic mechanisms of $\mathrm{CCMs}^{10)}$. VEGF seems to be involved in the proliferation of new vessels, such as CCMs, and small vessels within the

- Received : December 15, 2015 • Revised : March 11, 2016 • Accepted : April 7, 2016

- Address for reprints : Seong-Hyun Park, M.D., Ph.D.

Department of Neurosurgery, Kyungpook National University Hospital, 130 Dongdeok-ro, Jung-gu, Daegu 41944, Korea

Tel : +82-53-200-5652, Fax : +82-53-423-0504, E-mail : nsdoctor@naver.com

- This is an Open Access article distributed under the terms of the Creative Commons Attribution Non-Commercial License (http://creativecommons.org/licenses/by-nc/3.0) which permits unrestricted non-commercial use, distribution, and reproduction in any medium, provided the original work is properly cited. 
surrounding gliotic brain ${ }^{28)}$. Increased local expression of VEGF has been found in resected CCMs, leading to the hypothesis that VEGF may be related to the proliferation and hemorrhage of $\mathrm{CCMs}^{28,33,35)}$.

CCMs appear to grow by a process of vascular proliferation in the setting of repetitive lesional hemorrhages and exhibit brittle vascular morphology devoid of smooth muscle and elastin layers ${ }^{27)}$. CCMs do not exhibit the high-flow features of AVMs and are less commonly associated with apoplectic hemorrhage ${ }^{15)}$. CCM treatment with neurosurgical excision or stereotactic radiosurgery (SRS) aims to decrease the risk of intracranial hemorrhage. SRS can provide a reduction in hemorrhagic risk after an initial latency interval among patients with high risk CCMs. Inhibition of angiogenesis might represent a suitable complementary strategy for the treatment of angiogenesis-associated diseases. Although some studies have investigated local expression of angiogenic factors in CCMs, none has evaluated plasma VEGF levels in patients with CCM after radiosurgery. Recently, increased local and systemic VEGF levels have been reported in CCM patients with dynamic and progressive course ${ }^{10)}$. In this study, we evaluated plasma VEGF levels in patients with CCM before and after SRS. We hypothesized that patients with CCM would have changes in systemic VEGF levels and that this would normalize after radiosurgery.

\section{MATERIALS AND METHODS}

\section{Patient population}

Six patients with CCM who provided written informed consent were enrolled in this prospective protocol that was reviewed and approved by the Institutional Review Board of our hospital. All patients underwent SRS as the primary treatment for CCMs. Patients were selected for radiosurgery when CCM caused multiple, symptomatic hemorrhage. SRS was considered for patients with deep-seated CCM in a highly eloquent area that made microsurgical approach a high risk treatment. Peripheral blood samples donated from 10 volunteers without known malignancy or pregnancy were used as controls.

\section{Sample collection and enzyme-linked immunosorbent assays for VEGF}

Peripheral venous whole blood was obtained before radiosurgery (baseline sample) and 1 week, 1 month, 3 months, and 6 months after SRS. Blood samples from study participants were collected in citrate-supplemented tubes and centrifuged at 3200 rpm for 10 minutes at $4^{\circ} \mathrm{C}$. The supernatant including the plasma fraction was transferred to a microtube and frozen immediately at $-80^{\circ} \mathrm{C}$ until analysis. The analysis was performed with commercially available ELISA kits (Quantikine ${ }^{\circledR}$ Human VEGF Immunoassay, R\&D Systems, Minneapolis, MN, USA), according to the manufacturer's instructions. All patient samples collected were assayed simultaneously.

\section{Radiosurgical technique and follow-up}

SRS was carried out using a Gamma Knife Model C (Elekta AB, Stockholm, Sweden). T1-, T2-, and enhanced T1-weighted magnetic resonance imaging (MRI) with a slice thickness of 2 $\mathrm{mm}$ was used for 3-dimensional reconstructions and treatment planning. The MRIs were transferred to a workstation for postprocessing and analysis. The Gamma Plan system was used to determine the SRS for all patients. Multiple small isocenters were used to deliver a highly conformal dose to the lesion. CCM volume ranged from 0.08 to $4.8 \mathrm{~mL}$ (mean, $1.57 \mathrm{~mL}$ ). Mean marginal dose was $14.5 \mathrm{~Gy}$ (range, 13-16 Gy). The 50\% isodose line was used as the margin in all patients. Maximum radiation dose was 26-32 Gy (mean, 29 Gy).

Rebleeding after SRS was defined as imaging evidence of a new blood density corresponding to a new neurological sign or symptom. Follow-up MR imaging was requested at 6-month intervals during the first 2 years after SRS, after which it was recommended on an annual basis.

\section{Statistical analysis}

All analyses were performed using SPSS 18.0 for Windows (SPSS Inc., Chicago, IL, USA). Because the data were not distributed normally, they were analyzed using the Wilcoxon's ranksum test, the Mann-Whitney U-test. Correlations were assessed using the nonparametric Spearman's rank correlation analysis. $p$-values $<0.05$ were considered significant.

\section{RESULTS}

Of the 6 consecutive patients enrolled, 4 were women and 2 were men (mean age, 50.7 years; range, $22-70$ years). Six men and 4 women with a mean age of 47.6 years (range $30-55$ years) were included as controls. All patients had multiple hemorrhage (mean 2.2, range 2-3). Blood samples were drawn from 6 CCM patients before SRS and 1week, 1 month, 3 months, and 6 months after SRS. The patient and CCM characteristics as well as the radiosurgical parameters, were summarized in Table 1. Following SRS, 2 hemorrhages were observed in the follow-up period. No radiosurgical complications were noted.

\section{Plasma VEGF concentrations in controls and patients}

Mean plasma VEGF concentrations in controls were $29.3 \mathrm{pg} /$

Table 1. Patient and cerebral cavernous malformation characteristics and radiosurgical parameters

\begin{tabular}{lc}
\hline \multicolumn{1}{c}{ Variable } & Mean (range) \\
\hline Age (years) & $50.7(22-70)$ \\
Gender (male : female) & $2: 4$ \\
Volume $(\mathrm{mL})$ & $1.57(0.08-4.8)$ \\
Rebleeding after radiosurgery & \\
$\quad$ Yes & $2(33.3 \%)$ \\
$\quad$ No & $4(66.7 \%)$ \\
Margin dose $(\mathrm{Gy})$ & $14.5(13-16)$ \\
Maximal dose $(\mathrm{Gy})$ & $29.0(26-32)$ \\
\hline
\end{tabular}


$\mathrm{mL}$. There was no significant differences in mean plasma VEGF levels between men and women. There was no correlation between mean plasma concentrations of VEGF levels and age.

Mean plasma VEGF level was $41.9 \mathrm{pg} / \mathrm{mL}$ (range, 11.71$114.94 \mathrm{pg} / \mathrm{mL}$ ) at baseline in patients with CCM and $29.3 \mathrm{pg} / \mathrm{mL}$ (range, 9.2-64.3 pg/mL) in the control group ( $p=0.828$ ) (Fig. 1).

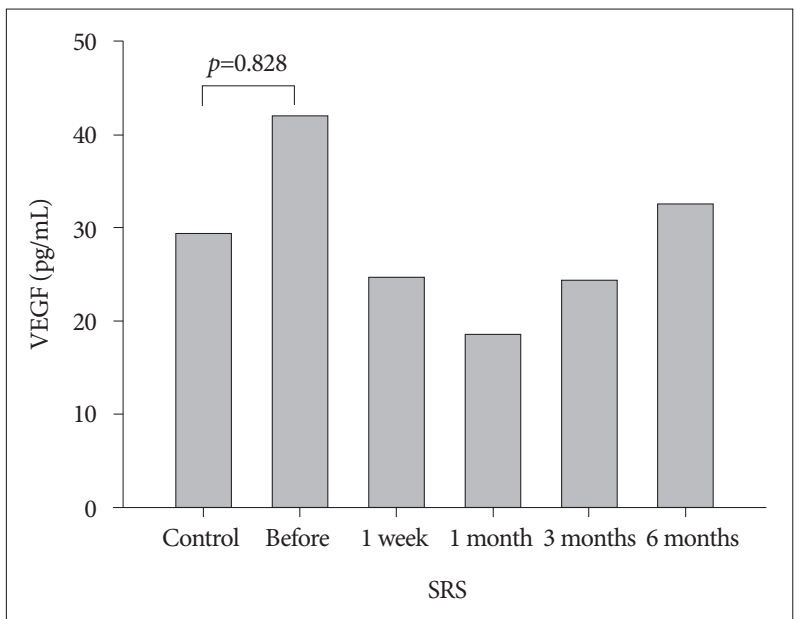

Fig. 1. Plasma concentrations of vascular endothelial growth factor (VEGF) in controls and patients with cerebral cavernous malformation before and after stereotactic radiosurgery (SRS).

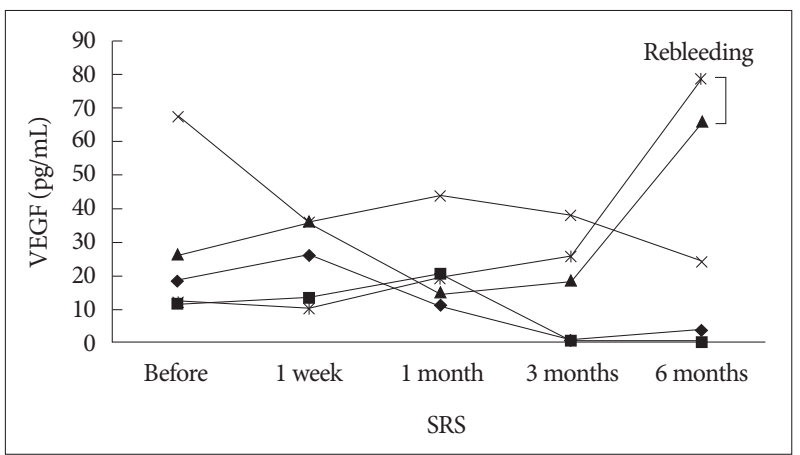

Fig. 2. Plasma concentrations of vascular endothelial growth factor (VEGF) in patients with cerebral cavernous malformation after stereotactic radiosurgery (SRS).
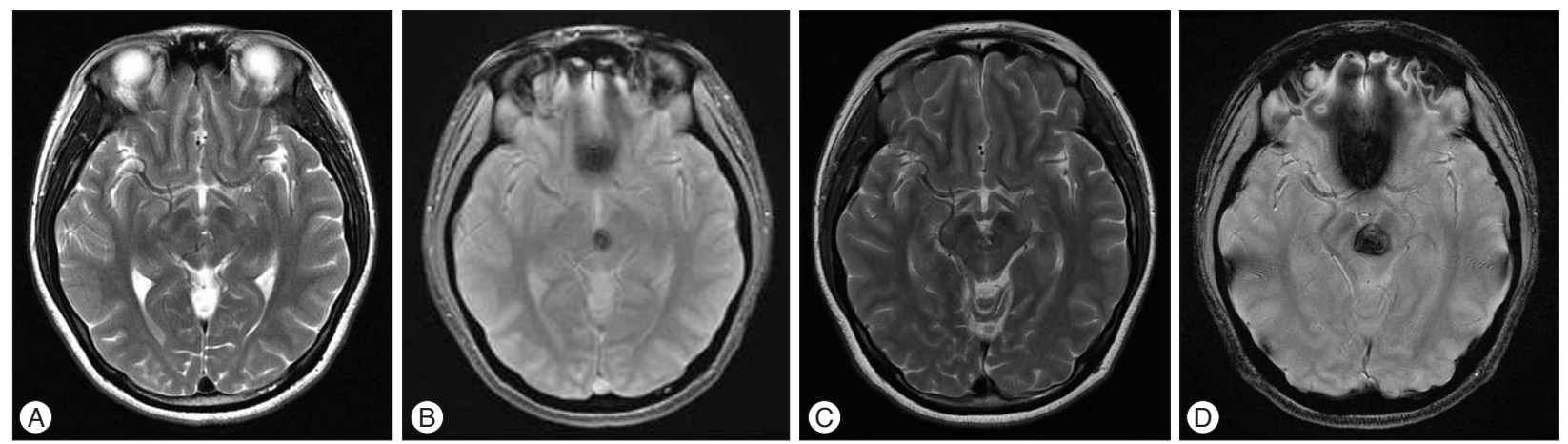

Fig. 3. T2-weighted (A) and gradient echo (B) magnetic resonance image (MRI) obtained in a 22-year-old woman with a cerebral cavernous malformation on midbrain. Stereotactic radiosurgery (SRS) was performed with a margin dose of 13 Gy to the $50 \%$ isodose line. The T2-weighted (C), gradient echo (D) MRI obtained 30 months after SRS shows a rebleeding on midbrain. Plasma vascular endothelial growth factor (VEGF) concentrations increased from $12.35 \mathrm{pg} / \mathrm{mL}$ to $78.56 \mathrm{pg} / \mathrm{mL} 6$ months after SRS.
Plasma VEGF levels in patients with CCM were higher than those in the control group; however, no significant difference was observed between the 2 groups. There was no significant difference in plasma VEGF levels between men and women $(p=$ $0.133)$. No correlation was observed between VEGF level and age $(p=0.072)$ or lesion volume $(p=0.623)$.

\section{Plasma VEGF concentrations after radiosurgery} surement of plasma VEGF concentrations before SRS and 1 week, 1 month, 3 months, and 6 months after SRS. Mean plasma VEGF level following SRS dropped from baseline level of $41.9 \mathrm{pg} / \mathrm{mL}$ to $24.6 \mathrm{pg} / \mathrm{mL}$ after 1 week, decreased to $18.5 \mathrm{pg} / \mathrm{mL}$ after 1 month, then increased to $24.3 \mathrm{pg} / \mathrm{mL}$ after 3 months, and finally $32.6 \mathrm{pg} / \mathrm{mL}$ after 6 months (Fig. 1). There was a trend toward decreased plasma VEGF concentrations 1 month after SRS, as compared to pretreatment levels. However, plasma VEGF levels 3 months and 6 months after SRS gradually increased. Plasma VEGF concentration 6 months after SRS was elevated over control levels, even though it was not significantly different from control levels (32.6 pg/mL vs. $29.3 \mathrm{pg} / \mathrm{mL}, p=1.000$ ).

Two patients suffering from rebleeding after SRS showed a higher level of VEGF at 6 months after SRS than the pretreatment level (Fig. 2). One patient experienced rebleeding from CCM on cerebellar hemisphere at 6 months following SRS, and baseline plasma VEGF level rose from $26.35 \mathrm{pg} / \mathrm{mL}$ to $65.68 \mathrm{pg} / \mathrm{mL}$ at 6 months after SRS (Table 2). The other experienced rebleeding from CCM on midbrain at 30 months after SRS (Fig. 3). Plasma VEGF levels at 6 months after SRS were $78.56 \mathrm{pg} / \mathrm{mL}$, which was significantly elevated over baseline level (12.35 pg/ $\mathrm{mL}$ ) before treatment.

The mean plasma VEGF levels in patients without rebleeding after SRS decreased from $53.2 \mathrm{pg} / \mathrm{mL}$ at baseline level to 12.8 $\mathrm{pg} / \mathrm{mL}$ at 6 months after SRS. However, plasma VEGF levels in patients suffering from rebleeding increased from $19.4 \mathrm{pg} / \mathrm{mL}$ to $72.1 \mathrm{pg} / \mathrm{mL}$ (Fig. 4). The pretreatment VEGF levels in the groups with/without rebleeding was not significantly different (19.4 pg/mL vs. $53.2 \mathrm{pg} / \mathrm{mL}$, respectively, $p=0.643$ ). However,
The effect of SRS for CCM was evaluated by sequential mea- 
Table 2. Demographic and clinical characteristics of 6 cerebral cavernous malformation patients

\begin{tabular}{|c|c|c|c|c|c|c|c|c|c|c|c|}
\hline \multirow{3}{*}{ No. } & \multirow{3}{*}{$\begin{array}{l}\text { Age/ } \\
\text { Sex }\end{array}$} & \multirow{3}{*}{ Location } & \multirow{3}{*}{ Symptom } & \multirow{3}{*}{$\begin{array}{c}\text { Volume } \\
(\mathrm{mL})\end{array}$} & \multirow{3}{*}{$\begin{array}{c}\text { Margin } \\
\text { dose } \\
(G y)\end{array}$} & \multicolumn{5}{|c|}{ VEGF (pg/mL) } & \multirow{3}{*}{$\begin{array}{l}\text { Rebleeding } \\
\text { after SRS }\end{array}$} \\
\hline & & & & & & \multirow{2}{*}{$\begin{array}{c}\text { SRS } \\
\text { Before }\end{array}$} & \multicolumn{4}{|c|}{ After SRS } & \\
\hline & & & & & & & 1 week & 1 month & 3 months & 6 months & \\
\hline 1 & $67 / \mathrm{F}$ & Cerebellum & Dizziness & 2.1 & 13 & 18.61 & 26.19 & 10.92 & 0.59 & 3.66 & - \\
\hline 2 & $39 / \mathrm{F}$ & Insula & Headache & 4.8 & 15 & 11.71 & 13.50 & 20.57 & 0.59 & 0.15 & - \\
\hline 3 & $45 / \mathrm{F}$ & Cerebellum & Headache & 0.7 & 15 & 26.35 & 35.92 & 14.72 & 18.28 & 65.68 & + \\
\hline 4 & $61 / \mathrm{M}$ & Insula & Headache & 0.23 & 16 & 67.40 & 35.89 & 43.79 & 37.93 & 24.35 & - \\
\hline 5 & $22 / \mathrm{F}$ & Midbrain & Diplopia & 0.08 & 13 & 12.35 & 10.26 & 19.19 & 25.78 & 78.56 & + \\
\hline 6 & $70 / \mathrm{M}$ & Temporal & Headache & 1.5 & 15 & 114.94 & 26.02 & 1.81 & 62.68 & 23.01 & - \\
\hline
\end{tabular}

VEGF : vascular endothelial growth factor, SRS : stereotactic radiosurgery

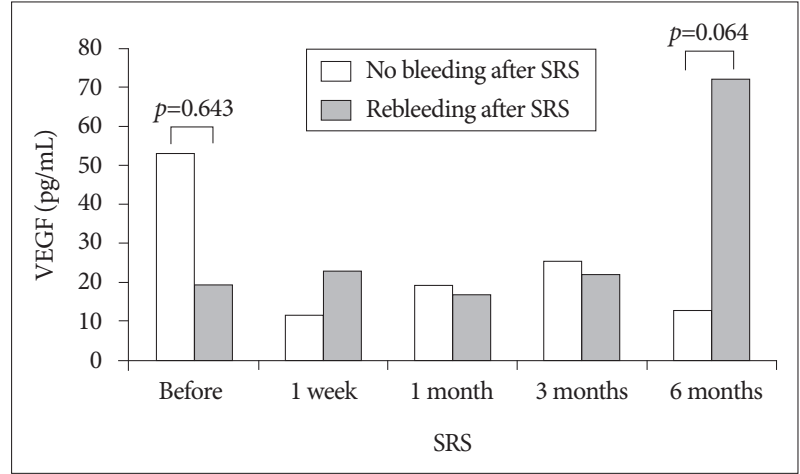

Fig. 4. Comparison of plasma vascular endothelial growth factor (VEGF) levels in patients with/without rebleeding after stereotactic radiosurgery (SRS) for cerebral cavernous malformation.

the difference of VEGF levels 6 months after SRS between the 2 groups was on the borderline for statistical significance $(p=0.064)$. Age, gender, lesion volume, and radiation dose were not significantly correlated with development of rebleeding following radiosurgery ( $p=0.165,0.467,0.165$, and 0.453 , respectively) (Table 3 ).

\section{DISCUSSION}

\section{VEGF, angiogenesis, and CCMs}

Plasma VEGF is detectable in the peripheral blood of normal healthy volunteers ${ }^{14)}$. The origin and biologic role of VEGF in healthy subjects are unknown; however, this finding suggests a role for endothelial mitogens in the maintenance of physiologic endothelial integrity. VEGF is a tyrosine kinase that plays an important role in angiogenesis and modulation of vascular permeability. VEGFs and their endothelial cell specific protein tyrosine kinase receptors (Flk-1, Flt-1), mediate various facets of blood vessel formation during vascular response to injury and disease ${ }^{4,35)}$. Studies have hypothesized that this may be a major regulator for inducing neovascularization in human cerebrovascular malformations and a key target for inhibiting angiogene$\mathrm{sis}^{21,28,33)}$. CCMs are thought to arise during the early stages of embryogenesis and to grow according to malformative mechanisms and blood-flow changes ${ }^{5,22,26,33)}$. The VEGFs and their receptors are usually down-regulated after birth, except under some physiologic or pathologic conditions. Recent studies have reported
Table 3. Characteristics of patients with/without rebleeding after stereotactic radiosurgery (SRS)

\begin{tabular}{lccc}
\hline \multicolumn{1}{c}{ Variable } & $\begin{array}{c}\text { Rebleeding }(-) \\
(\mathrm{n}=4)\end{array}$ & $\begin{array}{c}\text { Rebleeding }(+) \\
(\mathrm{n}=2)\end{array}$ & $p$ value \\
\hline Age & $59.3(39-70)$ & $33.5(22-45)$ & 0.165 \\
Female & 2 & 2 & 0.467 \\
Volume (mL) & $2.16(0.23-4.8)$ & $0.39(0.08-0.7)$ & 0.165 \\
Margin dose (Gy) & $14.8(13-16)$ & $14.0(13-15)$ & 0.453 \\
VEGF (pg/mL) & & & \\
$\quad$ Before SRS & 53.2 & 19.4 & 0.643 \\
$\quad$ After SRS & & & \\
$\quad$ 1 week & 25.4 & 23.1 & 1.000 \\
$\quad 1$ month & 19.3 & 17.0 & 1.000 \\
$\quad$ 3 months & 25.4 & 22.0 & 1.000 \\
$\quad 6$ months & 12.8 & 72.1 & 0.064 \\
\hline *Values expressed as the mean (range). VEGF $:$ vascur endotholial growth factor
\end{tabular}

*Values expressed as the mean (range). VEGF : vascular endothelial growth factor

the growth and de novo appearance of CCMs ${ }^{9,10,25)}$. CCMs often show a dynamic course, and their biological activities are likely to be correlated with angiogenesis ${ }^{10}$. Although the underlying developmental and pathogenetic mechanisms of CCMs are not completely understood, VEGF has been suggested as a possible mediating factor.

We evaluated plasma VEGF levels in patients with CCM before and after SRS and in a control group. We studied changes in plasma VEGF levels in order to understand angiogenic mechanisms regulating CCMs and the anti-angiogenic effect of SRS. Plasma VEGF levels were lower in healthy controls in comparison to the CCM patients before radiosurgery, even though it was not statistically different. Plasma VEGF levels decreased at the 1 week and 1 month after radiosurgery, and increased over 6 months. At the 6 month follow-up, mean VEGF levels were lower than those of pretreatment levels and elevated over control levels.

\section{Expression of VEGF in CCMs}

VEGF is the most potent angiogenic factor known so far, and it has recently been implicated in the pathophysiology of CCMs. Some studies have reported that the expression of proliferating cell nuclear antigen was detected in the endothelium of CCMs, indicating growth potential in these lesions; the expression of VEGF was diffusely increased, and this correlated with the re- 
currence of cerebrovascular malformations ${ }^{18,19,31,35)}$. Sure et al. ${ }^{33)}$ reported that there is endothelial proliferation as well as neoangiogenesis in CCMs. The angiogenic ability of CCM was documented by the immunoreaction to VEGF and Flk-1 of endothelial cells, because these proteins are not detected in normal brain vessels. Uranishi et al. ${ }^{35)}$ demonstrated significant increased expression of Flt-1 and Flk-1 in endothelial cells of CCM in comparison with that of control brain tissue sample. Although many studies have shown increased local expression of VEGF in CCMs, the cause of increased systemic levels of VEGF remains still unclear ${ }^{21,28,33,35)}$. Increased local expression of VEGF was found in the CCM specimens, suggesting that VEGF originated from CCMs and may be related to their development. Our finding additionally showed that plasma VEGF levels were higher than controls at baseline; therefore, systemic VEGF may be a mediating factor in the development of CCMs.

\section{Radiosurgery for CCMs}

Recurrent bleeding from CCMs is related to significant morbidity over the lifetime of a patient. Patients with symptomatic, recurrent CCM usually undergo surgical resection as primary treatment; however, complete resection of CCM at a high risk location is often difficult. SRS is an effective and well-tolerated management option for CCMs. Anti-angiogenic action of radiosurgery may be attributed, at least in part, to reduce a hemorrhagic tendency of CCMs. However, it is not clear why the risk of hemorrhage is reduced after radiosurgery. Unlike with AVMs, there is little pathological study about CCMs after radiation. Kondziolka et al. ${ }^{13)}$ suggested that the endothelial-lined channels undergo progressive hyalinization leading to thickening and eventual luminal closure, perhaps via the chronic inflammatory response typical of radiation-induced vasculopathy. Lunsford et al. ${ }^{16)}$ reported that the microvasculature of a CCM ultimately responds to radiosurgery in the same way AVMs respond. Nyáry et al. ${ }^{23)}$ revealed that there was endothelial cell destruction in the CCMs, accompanied by marked fibrosis with hyaline degeneration and scar tissue formation in the connective tissue stroma of the irradiated CCM. These histopathological findings were similar to those described in AVM after SRS, and suggest that the ionizing effect of radiation energy evokes vascular and connective tissue stromal changes in CCMs, as well. Karlsson et al. ${ }^{12)}$ reported a patient whose CCM was resected after SRS; more than $70 \%$ of the lesion had been obliterated.

\section{Change in systemic VEGF level after radiosurgery}

Although it is not clear whether the systemic expression of VEGF occurs as a result of intracranial hemorrhage or CCM itself, serial plasma VEGF levels showed dynamic changes with response to SRS. Previous research also showed the changes of plasma VEGF levels following SRS for brain tumor ${ }^{24)}$. Radiosurgery may reduce the secretion of VEGF protein from CCMs, as well as brain tumors. The plasma VEGF levels in the patients with CCM dropped at 1 month after SRS, then increased at 6 months, and were elevated over control levels, confirming abnormal angiogenesis in CCM pathophysiology. This finding suggested that the natural history of a CCM is partially related to VEGF expression. Gamma Knife-irradiated CCM tissue may have significantly less angiogenic activity than that of a previously untreated CCM. Our results supported the anti-angiogenic effects of SRS, which may be important for treating CCMs.

\section{Rebleeding from CCMs}

In CCMs patients, angiogenesis plays an important role in the progression and hemorrhage. Unlike 4 patients, 2 patients experienced significantly increased VEGF levels at 6 months after SRS. These patients experienced rebleeding from CCM each 6 months and 30 months after SRS. Increased level of angiogenesis may imply hemorrhagic risk and further risk of morbidity. We hypothesized that systemic expression of VEGF may be related to the development of rebleeding in CCM patients. Although it is not clear whether the systemic expression of VEGF results in a delayed hemorrhagic event from CCM after SRS, our result demonstrated that VEGF may be one of the causative or mediating factors contributing to the dynamic activity of CCMs. Nagy et $\mathrm{al}^{20)}$ reported that CMs had multiple symptomatic hemorrhages before radiosurgery with a first-ever bleed rate of $2.9 \%$ per lesion per year, and a rebleed rate of $30.5 \%$ per lesion per year. In this group the rebleed rate decreased to $15 \%$ for the first 2 years after radiosurgery and declined further to $2.4 \%$ thereafter. Monitoring peripheral blood biomarkers in patients with CCM may be valuable for those with highly angiogenic diseases, which tend to rebleed. Jung et al. ${ }^{10)}$ reported that the clinical features, MR imaging patterns, and VEGF levels in their patients were stabilized by glucocorticoid treatment. Glucocorticoid has suppressive effects on the expression of VEGF ${ }^{17,21)}$. Administration of glucocorticoid at the time of a elevated VEGF expression may improve the dynamic behavior of CCMs through the downregulation of VEGF.

The results of our preliminary study suggested an increased expression of angiogenic factor in biologically active CCM, although this will need consensus from a larger number of cases. A better understanding of the role of abnormal angiogenesis in CCM patients may lead to improved patient management and novel therapeutic options. Increased systemic VEGF levels in $\mathrm{CM}$ patients may be limited as general screening test, because VEGF levels are elevated in a wide variety diseases. However, serial measurement of VEGF levels would be helpful to monitor hemorrhage, growth, and treatment response of CCMs.

The main limitations of our study were the small data set and the short follow-up period. The small sample size resulted in confusion of statistical analysis and sensitive change of plasma levels. Six month follow-up may not have been sufficient to observe a change in VEGF levels. Analysis of our results may have been limited by the selection bias of healthy controls as well as patients. Sufficient plasma VEGF data in a control group and abnormal levels in patients with CCM are needed to establish them 
as biomarkers and a diagnostic tool to monitor the effects of treatment. A high-quality prospective study with a long-term followup is necessary to investigate the anti-angiogenic effect of SRS in patients with CCM.

\section{CONCLUSION}

Plasma VEGF levels in patients with CCM are elevated over controls at baseline, decrease at 1 month after SRS, and then increase at 6 months after SRS. This was a preliminary study on the potential association between plasma VEGF levels and CCMs. Our results have implications for further research on determining whether plasma VEGF levels could be useful to monitor the treatment efficacy after SRS.

\section{- Acknowledgements \\ This work was supported by Biomedical Research Institute grant, Kyung- pook National University Hospital (2012).}

\section{References}

1. Bobik A, Campbell JH : Vascular derived growth factors : cell biology, pathophysiology, and pharmacology. Pharmacol Rev 45 : 1-42, 1993

2. Brauer MJ, Zhuang G, Schmidt M, Yao J, Wu X, Kaminker JS, et al. : Identification and analysis of in vivo VEGF downstream markers link VEGF pathway activity with efficacy of anti-VEGF therapies. Clin Cancer Res 19: 3681-3692, 2013

3. Brogi E, Wu T, Namiki A, Isner JM : Indirect angiogenic cytokines upregulate VEGF and bFGF gene expression in vascular smooth muscle cells, whereas hypoxia upregulates VEGF expression only. Circulation 90 : 649652, 1994

4. Challa VR, Moody DM, Brown WR : Vascular malformations of the central nervous system. J Neuropathol Exp Neurol 54 : 609-621, 1995

5. Clatterbuck RE, Moriarity JL, Elmaci I, Lee RR, Breiter SN, Rigamonti $\mathrm{D}$ : Dynamic nature of cavernous malformations : a prospective magnetic resonance imaging study with volumetric analysis. J Neurosurg 93 : 981-986, 2000

6. Criscuolo GR, Merrill MJ, Oldfield EH : Further characterization of malignant glioma-derived vascular permeability factor. J Neurosurg 69 : 254-262, 1988

7. de Vries C, Escobedo JA, Ueno H, Houck K, Ferrara N, Williams LT : The fms-like tyrosine kinase, a receptor for vascular endothelial growth factor. Science 255 : 989-991, 1992

8. Ferrara $\mathrm{N}$ : Vascular endothelial growth factor and the regulation of angiogenesis. Recent Prog Horm Res 55 : 15-35; discussion 35-36, 2000

9. Houtteville JP : Brain cavernoma : a dynamic lesion. Surg Neurol 48 : 610-614, 1997

10. Jung KH, Chu K, Jeong SW, Park HK, Bae HJ, Yoon BW : Cerebral cavernous malformations with dynamic and progressive course : correlation study with vascular endothelial growth factor. Arch Neurol 60 : 16131618, 2003

11. Kappel A, Rönicke V, Damert A, Flamme I, Risau W, Breier G : Identification of vascular endothelial growth factor (VEGF) receptor-2 (Flk-1) promoter/enhancer sequences sufficient for angioblast and endothelial cell-specific transcription in transgenic mice. Blood 93 : 4284-4292, 1999

12. Karlsson B, Kihlström L, Lindquist C, Ericson K, Steiner L : Radiosurgery for cavernous malformations. J Neurosurg 88 : 293-297, 1998

13. Kondziolka D, Lunsford LD, Flickinger JC, Kestle JR : Reduction of hemorrhage risk after stereotactic radiosurgery for cavernous malfor- mations. J Neurosurg 83 : 825-831, 1995

14. Kraft A, Weindel K, Ochs A, Marth C, Zmija J, Schumacher P, et al. : Vascular endothelial growth factor in the sera and effusions of patients with malignant and nonmalignant disease. Cancer 85 : 178-187, 1999

15. Little JR, Awad IA, Jones SC, Ebrahim ZY : Vascular pressures and cortical blood flow in cavernous angioma of the brain. J Neurosurg 73 : 555559, 1990

16. Lunsford LD, Kondziolka D, Flickinger JC, Bissonette DJ, Jungreis CA, Maitz AH, et al. : Stereotactic radiosurgery for arteriovenous malformations of the brain. J Neurosurg 75 : 512-524, 1991

17. Machein MR, Kullmer J, Rönicke V, Machein U, Krieg M, Damert A, et al. : Differential downregulation of vascular endothelial growth factor by dexamethasone in normoxic and hypoxic rat glioma cells. Neuropathol Appl Neurobiol 25 : 104-112, 1999

18. Marti HH, Risau W : Systemic hypoxia changes the organ-specific distribution of vascular endothelial growth factor and its receptors. Proc Natl Acad Sci U S A 95 : 15809-15814, 1998

19. Monacci WT, Merrill MJ, Oldfield EH : Expression of vascular permeability factor/vascular endothelial growth factor in normal rat tissues. Am J Physiol 264 (4 Pt 1) : C995-C1002, 1993

20. Nagy G, Razak A, Rowe JG, Hodgson TJ, Coley SC, Radatz MW, et al. : Stereotactic radiosurgery for deep-seated cavernous malformations : a move toward more active, early intervention. Clinical article. J Neurosurg 113 : 691-699, 2010

21. Nauck M, Karakiulakis G, Perruchoud AP, Papakonstantinou E, Roth M: Corticosteroids inhibit the expression of the vascular endothelial growth factor gene in human vascular smooth muscle cells. Eur J Pharmacol $341: 309-315,1998$

22. Notelet L, Houtteville JP, Khoury S, Lechevalier B, Chapon F : Proliferating cell nuclear antigen (PCNA) in cerebral cavernomas : an immunocytochemical study of 42 cases. Surg Neurol 47 : 364-370, 1997

23. Nyáry I, Major O, Hanzély Z, Szeifert GT : Histopathological findings in a surgically resected thalamic cavernous hemangioma 1 year after 40-Gy irradiation. J Neurosurg 102 Suppl : 56-58, 2005

24. Park SH, Hwang JH, Hwang SK: Change in plasma vascular endothelial growth factor after gamma knife radiosurgery for meningioma : a preliminary study. J Korean Neurosurg Soc 57 : 77-81, 2015

25. Pozzati E, Acciarri N, Tognetti F, Marliani F, Giangaspero F : Growth, subsequent bleeding, and de novo appearance of cerebral cavernous angiomas. Neurosurgery 38 : 662-669; discussion 669-670, 1996

26. Robinson JR, Awad IA, Little JR : Natural history of the cavernous angioma. J Neurosurg 75 : 709-714, 1991

27. Robinson JR Jr, Awad IA, Zhou P, Barna BP, Estes ML : Expression of basement membrane and endothelial cell adhesion molecules in vascular malformations of the brain : preliminary observations and working hypothesis. Neurol Res 17 : 49-58, 1995

28. Rothbart D, Awad IA, Lee J, Kim J, Harbaugh R, Criscuolo GR : Expression of angiogenic factors and structural proteins in central nervous system vascular malformations. Neurosurgery 38 : 915-924; discussion 924-925, 1996

29. Shifren JL, Doldi N, Ferrara N, Mesiano S, Jaffe RB : In the human fetus, vascular endothelial growth factor is expressed in epithelial cells and myocytes, but not vascular endothelium : implications for mode of action. J Clin Endocrinol Metab 79: 316-322, 1994

30. Shweiki D, Itin A, Soffer D, Keshet E : Vascular endothelial growth factor induced by hypoxia may mediate hypoxia-initiated angiogenesis. Nature 359: 843-845, 1992

31. Sonstein WJ, Kader A, Michelsen WJ, Llena JF, Hirano A, Casper D : Expression of vascular endothelial growth factor in pediatric and adult cerebral arteriovenous malformations : an immunocytochemical study. J Neurosurg 85 : 838-845, 1996

32. Strugar JG, Criscuolo GR, Rothbart D, Harrington WN : Vascular endo- 
thelial growth/permeability factor expression in human glioma specimens : correlation with vasogenic brain edema and tumor-associated cysts. J Neurosurg 83 : 682-689, 1995

33. Sure U, Butz N, Schlegel J, Siegel AM, Wakat JP, Mennel HD, et al. : Endothelial proliferation, neoangiogenesis, and potential de novo generation of cerebrovascular malformations. J Neurosurg 94 : 972-977, 2001

34. Terman B, Khandke L, Dougher-Vermazan M, Maglione D, Lassam NJ, Gospodarowicz D, et al. : VEGF receptor subtypes KDR and FLT1 show different sensitivities to heparin and placenta growth factor. Growth
Factors $11: 187-195,1994$

35. Uranishi R, Baev NI, Ng PY, Kim JH, Awad IA : Expression of endothelial cell angiogenesis receptors in human cerebrovascular malformations. Neurosurgery 48 : 359-367; discussion 367-368, 2001

36. Wizigmann-Voos S, Breier G, Risau W, Plate KH : Up-regulation of vascular endothelial growth factor and its receptors in von Hippel-Lindau disease-associated and sporadic hemangioblastomas. Cancer Res 55 : 1358-1364, 1995 